\title{
As perspectivas de graduandos da área de saúde quanto ao Sistema Único de Saúde e a graduação
}

\author{
Paula Torres Trivellato, Renato Pereira da Silva, Sílvia Oliveira Lopes, Elizângela da Silva Miguel
}

\begin{abstract}
Resumo
A construção de um modelo de atenção à saúde integral e de qualidade, requer formação de recursos humanos aptos a trabalhar e a fortalecer o sistema público de saúde. Para essa construção é necessário colocar em pauta a responsabilidade das instituições de ensino e os anseios dos futuros profissionais de saúde frente ao Sistema Único de Saúde (SUS). Verificar a perspectiva profissional e avaliação do curso de graduação por estudantes de nutrição, medicina e enfermagem quanto ao SUS. Estudo transversal realizado com estudantes do último ano de graduação dos cursos de nutrição, medicina e enfermagem da Universidade Federal de Viçosa-UFV. A coleta dos dados se deu mediante aplicação de um questionário estruturado. Foram levantadas informações sobre o SUS enquanto política pública e mercado de trabalho e a influência da graduação na orientação profissional e nos conhecimentos sobre este sistema. A tabulação dos dados foi realizada no Software Microsoft Excel. O presente trabalho foi submetido ao Comitê de Ética e Pesquisa com Seres Humanos da Universidade Federal de Viçosa (687.930/2014) e a participação foi mediante a assinatura do Termo de Consentimento Livre e Esclarecido. Foram entrevistados 69 estudantes, sendo $29 \%(n=20)$ do curso de medicina, 33\% ( $n=23)$ de nutrição e $38 \%(n=26)$ de enfermagem. A maioria $60,9 \%(n=42)$ do total de estudantes analisados considerou o SUS uma política pública de sucesso; 92,3\% $(n=24)$ dos estudantes de enfermagem e $80 \%(n=16)$ dos estudantes de medicina disseram pretenderem trabalhar no SUS. No curso de nutrição prevaleceu a não pretensão de trabalhar no SUS $(52,2 \%)$. Do total de participantes, $65,2 \%(n=45)$ consideraram a graduação muito importante para a formação dos seus conhecimentos sobre o SUS. 39\% $(n=9)$ dos estudantes de nutrição e $76,9 \%(n=20)$ dos estudantes de enfermagem disseram que a graduação o estimula a trabalhar no SUS, no curso de medicina não houve diferença entre as respostas. Os estudantes entrevistados dos cursos da área de saúde da UFV, em sua maioria, tiveram uma avaliação positiva do SUS e da graduação como estímulo ao trabalho na saúde pública e responsável pelos seus conhecimentos sobre o sistema. Esse fato elucida o compromisso social da instituição na formação de recursos humanos para o sistema público de saúde. Porém ainda é preciso melhorar algumas perspectivas, crescer mais a causa social que envolve a criação desse sistema e enraizar seus princípios.
\end{abstract}

Descritores: Graduação; Saúde Pública; Sistema Único de Saúde. 